\title{
Exhaust Heat Recovery of Jaggery Making Furnace
}

\author{
Appasaheb Manjare ${ }^{1}$, Jitendra Hole ${ }^{2}$ \\ ${ }^{1,2}$ Mechanical Engineering Department RSCOE, Tathawade, Savitribai Phule Pune University, \\ Pune - Bombay Highway, Pune- 411038, India
}

\begin{abstract}
Jaggery making from the sugarcane is a traditional process which creates local employments and entrepreneurship opportunities. Jaggery making plants are generally small units fabricated by local artisans on the basis of age old expertise without any technical support. Bagasse is used as fuel to boil the sugarcane juice. In traditional single pan jaggery furnace due to incomplete combustion of bagasse energy losses are high resulting into higher fuel consumption and low thermal efficiency of the plat. In order to reduce the losses and cut down the consumption of bagasse, exhaust heat is utilized for preheating of sugarcane juice in pre-heater. The improved plant and the conventional plant are compared on the basis of thermal efficiency and bagasse consumption per Kg jaggery production. Resulted that thermal efficiency is improved from $16.16 \%$ to $24.36 \%$ and bagasse consumption is reduced by $1.2 \mathrm{Kg}$ per Kg jaggery production.
\end{abstract}

Keywords: single pan jaggery furnace, Boiling Pan, Pre-heating, Bagasse, Thermal efficiency

\section{Introduction}

Sugarcane occupies an important position in agrarian economy of India. About 6 million farmers and a large number of agricultural labours are involved in cane cultivation. The area under sugarcane is hovering around 4.4 million hectares and with an average productivity of 68 tonnes/hectare. On an average, white sugar production accounts for nearly 60 percent of the total cane produced in the country, 15-20 percent sugarcane is utilized for Jaggery production and rest is utilized for other purposes including seed.

Jaggery production in our country is a traditionally, labourintensive cottage industry, mostly, confined to rural areas. There is a general thought that jaggery is a common sweetener of the poor. However, it is fairly consumed in almost all sections of society. Jaggery is an eco-friendly sweetener and meets about 40 percent demand of sweeteners in the country. Jaggery has been in use as energy food and sweetening base for a number of preparations since the time immemorial. The important traditional sweetener is commonly known as Gur in India, Desi in Pakistan, Panela in South America and Jaggery in African countries. The art of manufacturing jaggery [1].

\section{Problem Definition}

Jaggery making from the sugarcane is a traditional process which creates local employments and entrepreneurship opportunities. Jaggery making plants are generally small units fabricated by local artisans on the basis of age old expertise without any technical support. Bagasse is used as fuel for jaggery production. In traditional jaggery furnace due to incomplete combustion of bagasse energy losses are high resulting into higher fuel consumption and low thermal efficiency of the plant.

In order to reduce the losses and cut down the consumption of bagasse, exhaust heat is utilized for preheating of sugarcane juice in pre-heater and economizer. The improved plant and the conventional plant are compared on the basis of thermal efficiency, bagasse consumption per kg jaggery production and production time. This project has a potential to reduce the fuel consumption and improve the thermal efficiency of the jaggery making furnace.

\section{Jaggery Making Process}

Process of jaggery making is almost same in every part of the Indian sub-continent but there is a difference in the design of plants being used for jaggery making. In the northern Indian states of Uttar Pradesh and Uttarakhand, three pan jaggery making plant is popular, however in the state of Maharashtra single pan and four pan plants are popular. Jaggery making from the sugarcane is a traditional process which creates local employments and entrepreneurship opportunities [2].

Jaggery making plants are generally small units fabricated by local artisans on the basis of age old expertise without any technical support. It mainly consists of an underground furnace, like an open pan cooking stove (bigger version of a biomass based cooking stove) with a pan mounted on to it for evaporating the juice. The process flow diagram for jaggery plant is presented in Figure 1.

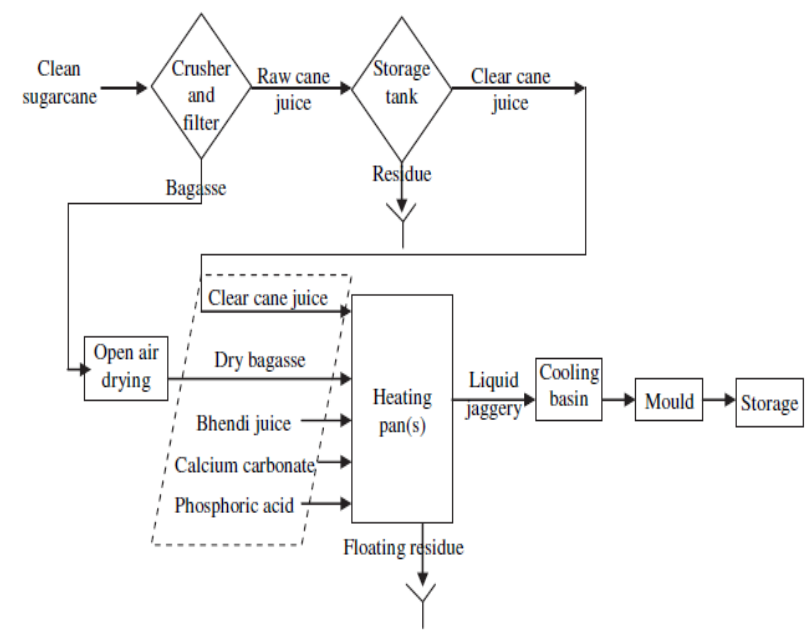

Figure 1: Process flow diagram for jaggery plant 


\section{International Journal of Science and Research (IJSR) \\ ISSN (Online): 2319-7064 \\ Index Copernicus Value (2013): 6.14 | Impact Factor (2015): 6.391}

Almost all the jaggery units use bagasse (a residue left after juice extraction from sugarcane) as a fuel to meet the energy requirement for the concentration of sugar cane juice. Bagasse is burnt in a furnace to provide required heat for evaporation of sugarcane juice. Variation in moisture content of sun dried bagasse affects performance of jaggery making furnaces.

There are two types of jaggery furnace single pan furnace and multiple pans (Two to Four pans) furnace. In a single pan furnace all jaggery making processes like sensible heating, chemical addition, impurity removal, evaporation etc. are carried out in single pan as a batch process, while in a multiple pan furnace above jaggery making processes are carried out in three to four pans in a semi- continuous mode [3].

\section{Traditional Jaggery Furnace}

In order to evaluate the system performance of jaggery making furnace, various details such as juice recovery obtained after crushing sugarcane, amount of bagasse obtained, the moisture content before and after sun drying, the amount and frequency of feeding bagasse into the furnace were noted. The temperature of juice during boiling and the temperature of flue gas were also observed.

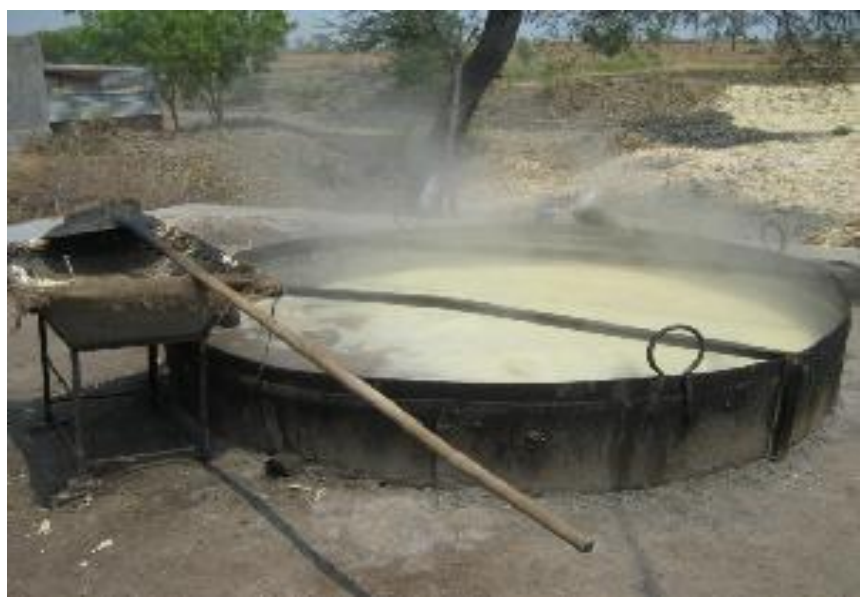

Figure 2: Traditional Jaggery Making Plant

\subsection{Observations}

1) Mass of sugarcane juice per batch $=840 \mathrm{~kg}$

2) Mass of bagasse required per batch $=580 \mathrm{~kg}$

3) Mass of jaggery produced per batch $=175 \mathrm{~kg}$

4) Mass of slag (mud) removed per batch $=25 \mathrm{~kg}$

5) Mass of water evaporated per batch $=640 \mathrm{~kg}$

6) Initial room temperature of furnace $=33^{\circ} \mathrm{C}$.

7) Initial temperature of juice $=30^{\circ} \mathrm{C}$.

8) Final temperature of juice $=95^{\circ} \mathrm{C}$

9) Flue gas temperature near about $240^{\circ} \mathrm{C}$

10) The inside temperature of furnace during combustion $=$ 500 to $600^{\circ} \mathrm{C}$

11) Time required for one batch $=2.5$ hours

\subsection{Calculations:}

1) Heat energy input per batch $=\mathrm{mb} * \mathrm{Cb}$

$$
\begin{aligned}
& =580 * 18000 \\
& =10440 \mathrm{MJ}
\end{aligned}
$$

2) Energy required for heating the juice:

$$
\begin{aligned}
& =\mathrm{mj} * \mathrm{CPw} *(\mathrm{Tj}-\mathrm{Ta}) \\
& =840 * 4.187 *(95-30) \\
& =218.05 \mathrm{MJ}
\end{aligned}
$$

Latent heat of water $=2270 \mathrm{~kJ} / \mathrm{kg}$

3) Mass of water evaporated per batch :

Mass of jaggery produced $=$ mass of juice - mass

of water evaporated - mass of slag

$$
\begin{aligned}
& 175=840-\mathrm{mw}-25 \\
& \mathrm{Mw}=640 \mathrm{~kg}
\end{aligned}
$$

4) Total latent heat of vaporization of water :

$$
\begin{aligned}
& =\mathrm{Mw} * \mathrm{hfg} \\
& =640 * 2270 \\
& =1453.44 \mathrm{MJ}
\end{aligned}
$$

5) Total heat of evaporation required was :

$=$ Heat energy required for heating the juice + Total latent heat of vaporization of water

$$
\begin{aligned}
& =218.05+1453.44 \\
& =1671.49 \mathrm{MJ}
\end{aligned}
$$

6) Thermal efficiency $=\frac{\text { Heat output }}{\text { Heat input }}$

$$
=\frac{1671.49}{10440}
$$

Thermal efficiency $=16.16 \%$

\section{Improved Jaggery furnace}

Tank is constructed around the chimney in which juice is poured. Juice absorbs the heat of the exhaust gas which is flowing through the chimney. It is observed that the temperature of the juice increased by $35^{\circ} \mathrm{C}$. Finally such heated juice poured in a boiling pan and efficiency calculated.

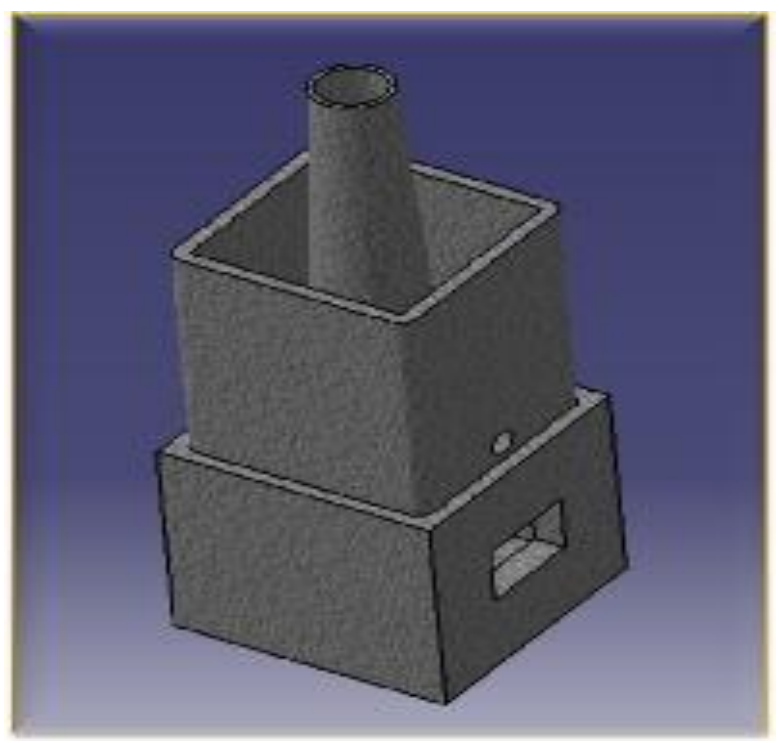

Figure 3: Modified chimney (Pre-Heater) 


\section{Result}

It is observed that, thermal efficiency of improved jaggery making furnace is $24.36 \%$, which is considerably increased than traditional plant.

\section{References}

[1] Vision 2030: Indian Institute of Sugarcane Research Lucknow, 2011 (Chapter 1).

[2] PVK Jagannadha, Madhusweta Das and SK Das, Jaggery, A Traditional Indian Sweetener, Indian Journal of Traditional Knowledge, Vol. 6(1), January 2007, pp 95102.

[3] Techno-Economic Analysis of Jaggery Production in Maharashtra: Indian Institute of Technology, Bombay, 2012, (Chapter 1, 2).

[4] Ganesh B. Agalave, Performance Improvement of a Single Pan Traditional Jaggery Making Furnace by Using Fins and Baffle, International Journal of Advance Research In Science And Engineering, IJARSE, Vol. No.4, Issue 04, April 2015. 